\title{
Acute bronchospasm and resolution captured on dynamic CT
}

This article was published in the following Dove Press journal:

Journal of Asthma and Allergy

30 October 2012

Number of times this article has been viewed

\section{Hayet Amalou \\ Bradford J Wood}

Center for Interventional Oncology, NIH Clinical Center, National Institutes of Health, Bethesda, MD, USA
Correspondence: Bradford J Wood Center for Interventional Oncology, MSC I 182, National Institutes of Health, Bethesda, MD 20892, USA

$\mathrm{Tel}+\mathrm{I} 30$ I 4967739

Fax + I 30I 45। 5726

Email bwood@nih.gov
Abstract: Computed tomography (CT) imaging provides a noninvasive window beneath the skin, defines lung pathology, and facilitates virtual and multimodality fusion interventions. A CT scan of acute bronchospasm is shown during a CT-guided lung intervention. Dynamic or sequential CT imaging can depict and perhaps even quantify acute reversible bronchospasm, and could potentially play a role in better understanding pharmacologic interventions for reactive airways and the resulting effects.

Keywords: acute bronchospasm, dynamic CT, albuterol, physiological response, noninvasive

\section{Introduction}

Acute bronchospasm is rarely imaged dynamically prior to and following successful therapy. The ability to quantify the presence or degree of bronchospasm and its response to therapies could potentially provide a tool for the analysis of bronchospasm. Recent low-dose CT scans can resolve the edge of the main airways with a fraction of the ionizing radiation.

\section{Case presentation}

A 62-year-old man with a long history of smoking and recently diagnosed chronic obstructive pulmonary disease had an acute episode of bronchospasm following a lung biopsy, which was seen dynamically on CT. The CT scan was performed sequentially over a limited field of view to monitor a very small asymptomatic pneumothorax for change in size after a percutaneous biopsy. This afforded the fortuitous opportunity to document the images of acute bronchospasm, including the response to the inhaled bronchodilator albuterol. Radiological and physiological response to albuterol correlated with the clinical resolution of hypoxia.

The patient underwent a biopsy to determine if a recently diagnosed lung mass was a primary lung cancer or recurrent lymphoma. Immediately after the removal of the biopsy needle, a CT scan demonstrated a very small (several $\mathrm{mm}$ ) asymptomatic pneumothorax. The patient was initially neither wheezing nor dyspneic or tachypneic. Ten minutes later, he suddenly began to wheeze and soon thereafter, his blood oxygen saturation levels suddenly and precipitously dropped from a baseline of $95 \%-96 \%$ to $88 \%$. A second immediate CT scan at the time of wheezing showed simultaneous acute narrowing of the trachea and both main bronchi (Figure 1A-F). CT scans prior to wheezing, while wheezing, and after treatment of wheezing and resolution 


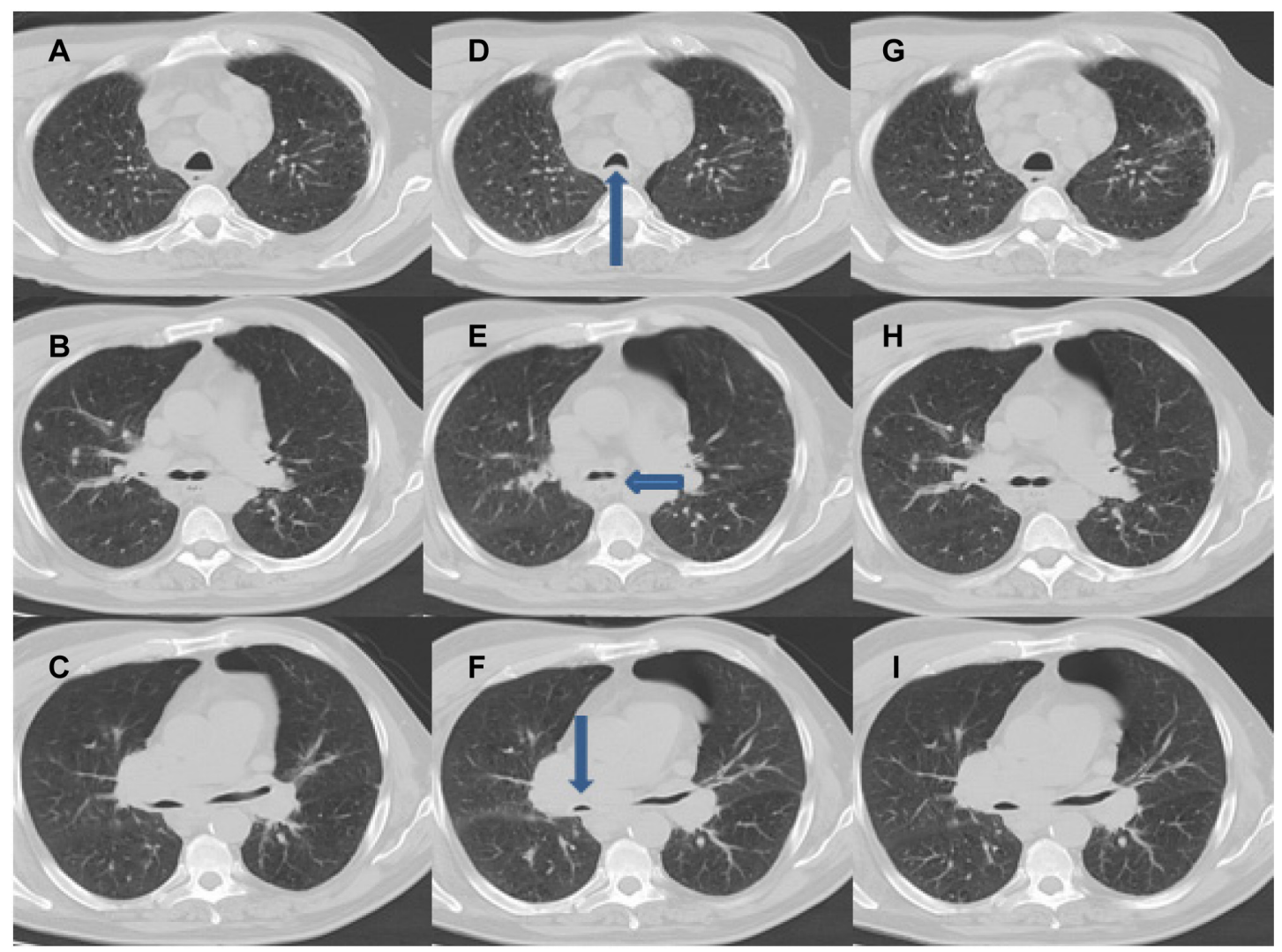

Figure I Acute bronchospasm on a computed tomography scan. (A-C) Baseline computed tomography images of the trachea, carina, and main bronchi. (D-F) Computed tomography images during acute bronchospasm at the trachea (arrow up), carina (arrow sideways), and main bronchi (right bronchus: arrow down). (G-I) Computed tomography images of the trachea, carina, and main bronchi 10 minutes after the administration of albuterol, which show resolution back to baseline.

of bronchospasm were each analyzed and measured at five levels for each time point (Table 1). The main trachea, right and left bronchi origins, and right and left main bronchi were measured in diameter at the same consistent levels, using anatomical landmarks as references. The CT during wheezing was obtained during a breath hold, without motion, on inspiration, and in between breaths. This was identical for all CT scans measured.

During wheezing, the tracheal area dropped by $52 \%$. The areas of the right and left bronchial origins (measured at the carina) decreased by $35 \%$ and $34 \%$, respectively. The right and left main bronchial areas decreased by
$72 \%$ and $68 \%$, respectively. A subsequent CT scan taken 10 minutes after administration of inhaled albuterol and resolution of wheeze showed resolution of size changes back to baseline (Figure 1G-I). It is possible, although speculative, that bronchial irritation from the biopsy or trace blood, in the presence of underlying reactive airways, triggered reflex bronchospasm.

\section{Discussion}

The dynamic imaging of bronchospasm and its response to therapy was a chance event for this patient. A chest CT is well established as the gold standard in structural imaging of

Table I Quantitative assessment of patient airways

\begin{tabular}{llllll}
\hline & $\begin{array}{l}\text { Baseline radius } \\
(\mathbf{c m})\end{array}$ & $\begin{array}{l}\text { Radius during spasm } \\
(\mathbf{c m})\end{array}$ & $\begin{array}{l}\text { Baseline area } \\
\left(\mathbf{c m}^{2}\right)\end{array}$ & $\begin{array}{l}\text { Area during spasm } \\
\left(\mathbf{c m}^{2}\right)\end{array}$ & $\begin{array}{l}\text { Percent change } \\
\text { in area }\end{array}$ \\
\hline $\begin{array}{l}\text { Trachea } \\
\text { Carina }\end{array}$ & & $16 \times 20$ & $9.1 \times 17.1$ & $-51.37 \%$ \\
Left & 4.0 & & & & $-34.0 \%$ \\
Right & 5.1 & 3.25 & 50.27 & 33.18 & $-35.37 \%$ \\
$\begin{array}{l}\text { Main bronchi } \\
\text { Left }\end{array}$ & 4.3 & 4.10 & 81.71 & 52.81 & $-67.53 \%$ \\
Right & 4.0 & 2.45 & 58.09 & 18.86 & $-72.45 \%$ \\
\hline
\end{tabular}


the bronchial tree. ${ }^{1}$ Clinical studies have shown a correlation between airway dimensions on CT and pulmonary function results in chronic obstructive pulmonary disease. ${ }^{2}$ Highresolution $\mathrm{CT}$ has been used effectively in assessing bronchial reactivity in asthmatic patients, and in assessing responses to both bronchoconstrictor and bronchodilator drugs. ${ }^{3,4}$ With recent advances in CT imaging technology, low-energy, lowdose CT scans could offer a method for noninvasive dynamic measurement of functional airway mechanics. Ultralow-dose CT scans can depict airways even with a fraction of the radiation of a usual CT, since the only thing that needs to be imaged in that setting is the air-bronchial wall interface, and that task may be accomplished with very low ionizing radiation dosage. Thus, such imaging methods could theoretically have potential as a noninvasive research tool to augment pulmonary function tests or quantitative video bronchoscopy ${ }^{1}$ in the future evaluation of bronchial dynamics and physiological responses to therapies.

\section{Acknowledgment}

This work was supported in part by the Center for Interventional Oncology and the Intramural Research Program of the National Institutes of Health.

\section{Disclosure}

The authors report no conflicts of interest in this work.

\section{References}

1. Czaja P, Soja J, Grzanka P, Cmiel A, Szczeklik A, Sladek K. Assessment of airway caliber in quantitative videobronchoscopy. Respiration. 2007;74(4):432-438.

2. Ohara T, Hirai T, Sato S, et al. Longitudinal study of airway dimensions in chronic obstructive pulmonary disease using computed tomography Respirology. 2008;13(3):372-378.

3. Schueller G, Neumann K, Helbich T, et al. Bronchial reactivity in hyperresponsive patients and healthy individuals: demonstration with high resolution computed tomography. Eur J Radiol. 2004;52(2):151-156.

4. Beigelman-Aubry C, Capderou A, Grenier PA, et al. Mild intermittent asthma: CT assessment of bronchial cross-sectional area and lung attenuation at controlled lung volume. Radiology. 2002;223(1): 181-187.

\section{Publish your work in this journal}

The Journal of Asthma and Allergy is an international, peer-reviewed open-access journal publishing original research, reports, editorials and commentaries on the following topics: Asthma; Pulmonary physiology; Asthma related clinical health; Clinical immunology and the immunological basis of disease; Pharmacological interventions and

\section{Dovepress}

new therapies. Issues of patient safety and quality of care will also be considered. The manuscript management system is completely online and includes a very quick and fair peer-review system, which is all easy to use. Visit http://www.dovepress.com/testimonials.php to read real quotes from published authors. 